between patients." This contrasts markedly with the coronary care unit in this study which was a light, active room in which considerable interaction took place between patients and between patients and nursing and medical staff.

An attempt has been made to assess the factors influencing the patients long-term rehabilitation. Persisting physical disability and personality factors appear to be most closely related. It was apparent from the separate interviews with husband and wife that patients who had previously had difficulty in coping with stress were those who found the cardiac arrest most threatening. Rehabilitation did not appear to be significantly influenced by factors related to the cardiac arrest, such as the duration of external cardiac massage or the duration of impaired consciousness following the arrest. Intellectual impairment, as judged by the spouse, was present in one patient at the time of discharge but was not found at the time of interview, supporting the view of previous authors (Dupont et al., 1969; McNamee et al., 1970) that this is an infrequent problem in patients surviving cardiac resuscitation.

The spouses particularly appreciated the opportunity given by the research interview to discuss their fears about the cardiac arrest and their husband's present health. The most prevalent and continual anxiety was that of recurrence of the cardiac arrest, and this resulted in several spouses being overprotective and restrictive about physical activities. Their efforts were concentrated on not upsetting the patient- "then I won't have any reason to feel guilty"-to the detriment of their own and their husbands' emotional well-being. Careful explanation and discussion with the spouse is necessary if they are to provide the support and encouragement required by the patient in the period after hospital discharge. Several wives felt that it would have been helpful to have had a further discussion with the physician before the patients' discharge and at the follow-up appointments if particular problems arose.
The occurrence of a cardiac arrest and the intensive care which followed led, in some patients, to feelings of dependency on the hospital. Initial follow-up outpatient visits often helped to reassure the patients and increase their self-confidence. Repeated outpatient visits, however, may lead to further unhelpful dependency on the hospital. A careful balance must therefore be sought so that the patient can be reassured at a suitable time that continuous hospital supervision is not necessary. In the absence of particular physical or severe psychological problems it would seem to be most helpful for the patient and if possible the spouse to be seen at least once fairly soon after discharge (one to two weeks) and perhaps again at two to three months to consider any problems related to their return to work. Long-term support may be required by some patients and by some spouses. This is probably best given by the general practitioner rather than the hospital.

We would like to thank the physicians and nursing staff concerned with the care of the patients and Dr. J. Dominian for his advice. M.D. and M.W.A. were receiving a research grant from the Ministry of Health and A.E.T. and M.W. McN. were receiving grants from the Medical Research Council.

\section{References}

Dominian, J., and Dobson, M. (1969). British Medical fournal, 4, 795. Druss, R. G., and Kornfeld, D. S. (1967). Fournal of the American Medical Association, 201, 291.

Dupont, B., Flensted-Jensen, E., and Sandøe, E. (1969). American Heart Fournal, 78, 444.

Hackett, T. P., Cassem, N. H., and Wishnie, H. A. (1968). New England Fournal of Medicine, 279, 1365 .

Hellerstein, H. K., and Ford, A. B. (1960). Circulation, 22, 1166

Johnson, A. L., Tanser, P. H., Ulan, R. A., and Wood, T. E. (1967) American fournal of Cardiology, 20, 831.

Lancet, $1969,2,262$.

Lancet, 1969, 2, 262.

McNamee, B. T. et al. (1970). British Medical fournal, 4, 204.

Seldon, W. A. (1963). Medical fournal of Australia, 2, 982.

\title{
Testosterone Therapy for Anaemia in Maintenance Dialysis
}

\author{
STANLEY SHALDON, KARL M. KOCH, FRITZ OPPERMANN, WOLF D. PATYNA, \\ WILLIAM SCHOEPPE
}

\section{Introduction}

\section{Summary}

Intramuscular testosterone 250-500 mg weekly given to 25 patients on long-term haemodialysis produced a significant rise in haemoglobin level in all patients. The response was reversible when the drug was stopped. Treatment was effective in bilaterally nephrectomized patients and those with intact kidney tissue. The use of intramuscular testosterone is recommended for all adult patients on long-term haemodialysis in order to eliminate the need for routine blood transfusions.

National Kidney Centre, London, N.3

STANLEY SHALDON, M.D., M.R.C.P., Medical Director

Department of Nephrology, Centre of Internal Medicine, University of Frankfurt, Frankfurt

KARL M. KOCH, M.D., Privat-dozent

FRITZ OPPERMANN, M.D., Resident

FRITZ OPPERMANN, M.D., Residen

WOLF D. PATYNA, M.D., Resident
WILLIAM SCHOEPPE, M.D., Privat-dozent
The anaemia associated with long-term haemodialysis still remains one of the relatively unsolved problems of this treatment. Since 1965 it has been possible to avoid routine blood transfusions in most dialysis patients (Shaldon, 1966) though the mean P.C.V. remains at $20 \%$ (Verroust et al., 1967). When patients thus treated have not previously received multiple blood transfusions they become iron-deficient from the repetitive blood loss associated with haemodialysis (Lawson et al., 1968), and a significant rise in haemoglobin levels has been reported with parenteral iron supplements (Comty et al., 1966; Crockett et al., 1967; Wright et al., 1968; Eschbach et al., 1970). However, in -spite of the hazards of hepatitis and increased transplant rejection rates associated with multiple blood transfusions (Parsons and Clark, 1969) only 10\% of haemodialysis patients were maintained on a non-transfusion policy in Europe in 1969 (Druckker et al., 1969).

Experimental evidence has suggested that androgens exert significant effects on erythropoiesis (Mirand et al., 1965; Fried and Gurney, 1968; Gordon et al., 1968). They have been used in a variety of refractory anaemias with widely varying responses. The most impressive clinical use has been in idiopathic aplastic anaemias of children (Shahidi and Dia- 
mond, 1961; Killander et al., 1969). It was therefore decided to evaluate androgen therapy in the anaemia of long-term haemodialysis patients in the hope that an overall improvement in haemoglobin levels could be obtained.

\section{Materials and Methods}

The androgen dose was $250 \mathrm{mg}$ of testosterone (Sustanon $250)$ as a mixture of its esters-propionate $(30 \mathrm{mg})$, phenylpropionate $(60 \mathrm{mg})$, isocaproate $(60 \mathrm{mg})$, and decanoate $(100$ $\mathrm{mg}$ )-given weekly by intramuscular injection, except in three bilaterally nephrectomized patients who received twiceweekly injections - that is, $500 \mathrm{mg} /$ week. The haemodialysis techniques used included: high-resistance two-layered Kiil dialyser with low blood volumes (priming volume including blood lines $250 \mathrm{ml}$ ) built with PT $150(11 \mu)$ shortway grain cuprophan wet stretched assembled with a consequent blood leak rate of less than $1 \%$, and individual patient heat-sterilized supply units with a pyrogen complication rate of less than $0.5^{\circ}$, . Access to the circulation was obtained by 14-gauge thin-walled steel needles using an arteriovenous fistula with blood pump and blood flows averaging $170 \mathrm{ml} / \mathrm{min}$. Dialysis time was 30 to 32 hours per week at three 10-hour or four eight-hour sessions, except in one patient (Case 24) in group $\mathrm{D}$ who received four 10-hour sessions per week.

The patients were divided into four groups (Table I-IV). Group A, six patients who were dialysed for 12 to 30 months without transfusions or testosterone and then received testosterone for six months and then stopped the androgen for at least six months. Group B, six patients who were transfused for emergency reasons of blood loss or infection during the first week of dialysing treatment and who then received androgen for six months. Group C, 10 new patients who were not transfused and started on androgen therapy when beginning dialysis and have continued for at least six months. Group D, three patients on dialysis for 3 to 24 months after bilateral nephrectomy before starting androgen therapy.

All patients were encouraged to eat a liberal protein diet $(1.25 \mathrm{~g} / \mathrm{kg}$ body weight), with an intake of $2,500-4,000$ calories per day. Oral and parenteral vitamin supplements including folate and vitamin $\mathrm{B}_{1: 2}$ were given regularly. Iron supplements as intravenous iron $100 \mathrm{mg} \times 10$ (course $1 \mathrm{~g}$ in 10 weeks) were given whenever serum iron levels fell below $60: \mathrm{g} 100 \mathrm{ml}$.

\section{Results}

In group A (Table 1) the mean P.C.V. rose from 24 to $34^{\prime}{ }_{0}$ within six months of starting testosterone and there was a universal fall to control values within six months of stopping testosterone (Fig. 1). The most satisfactory results were in Cases 1 and 2 where the P.C.V. rose above $20 \%$ for the first time and physical activity of a much more arduous nature became possible. Following the demonstration of a reversal of androgen effect all these patients were put back on maintenance doses of $250 \mathrm{mg}$ week.

Group B patients (Table II, Fig. 2) were all transfused during the first week of haemodialysis treatment for a variety of emergency reasons associated with blood loss at surgery or severe peritonitis complicating peritoneal dialysis. After transfusion there was a variable rise in P.C.V., and then patients were maintained on weekly testosterone and the P.C.V. continued to rise to a mean level of $30^{\circ} \%$. This response was unusual; previous experience with transfusions had led one to expect a fall in P.C.V. with time and then a plateau and possibly eventually a rise (Crockett et al., 1967).

Group C (Table III, Fig. 3) comprised 10 new patients, all managed by a standard dialysis policy and receiving androgen
TABLE I-Group $A$ Patients

\begin{tabular}{|c|c|c|c|c|c|c|c|}
\hline \multirow{2}{*}{$\begin{array}{l}\text { Case } \\
\text { No. }\end{array}$} & \multirow{2}{*}{ Sex } & \multirow{2}{*}{ Age } & \multirow{2}{*}{ Disease } & \multirow{2}{*}{$\begin{array}{c}\text { Months } \\
\text { on } \\
\text { Dialysis }\end{array}$} & \multicolumn{2}{|r|}{ P.C.V. (\%) } & \multirow{2}{*}{\begin{tabular}{|c|}
$\begin{array}{c}\text { Post- } \\
\text { androgent }\end{array}$ \\
\end{tabular}} \\
\hline & & & & & Control* & Androgen $\dagger$ & \\
\hline $\begin{array}{l}1 \\
2 \\
3 \\
4 \\
5 \\
6\end{array}$ & $\begin{array}{l}M \\
\mathbf{M} \\
\mathbf{F} \\
\mathbf{F} \\
\mathbf{M} \\
\mathbf{M}\end{array}$ & $\begin{array}{l}20 \\
24 \\
54 \\
58 \\
47 \\
36\end{array}$ & $\begin{array}{l}\text { GN } \\
\text { PN } \\
\text { PN } \\
\text { PN } \\
\text { GN } \\
\text { GN }\end{array}$ & $\begin{array}{l}34 \\
24 \\
24 \\
36 \\
42 \\
38\end{array}$ & $\begin{array}{l}16 \\
19 \\
21 \\
25 \\
31 \\
32\end{array}$ & $\begin{array}{l}23 \\
26 \\
28 \\
35 \\
42 \\
40\end{array}$ & $\begin{array}{l}17 \\
20 \\
21 \\
23 \\
28 \\
34\end{array}$ \\
\hline \multicolumn{5}{|r|}{ Mean } & 24 & 32 & 24 \\
\hline
\end{tabular}

$\mathrm{GN}=$ Glomerulonephritis. $\quad \mathbf{P N}=$ Pyelonephritis

"Control P.C.V. average from three months before androgen therapy and 12-30 months after starting dialysis.

months after starting dialysis.
†Androgen P.C.V. average from last three months of six-month period of androgen therapy.

Post-androgen P.C.V. average from three-month period, three months after stopping androgen therapy.

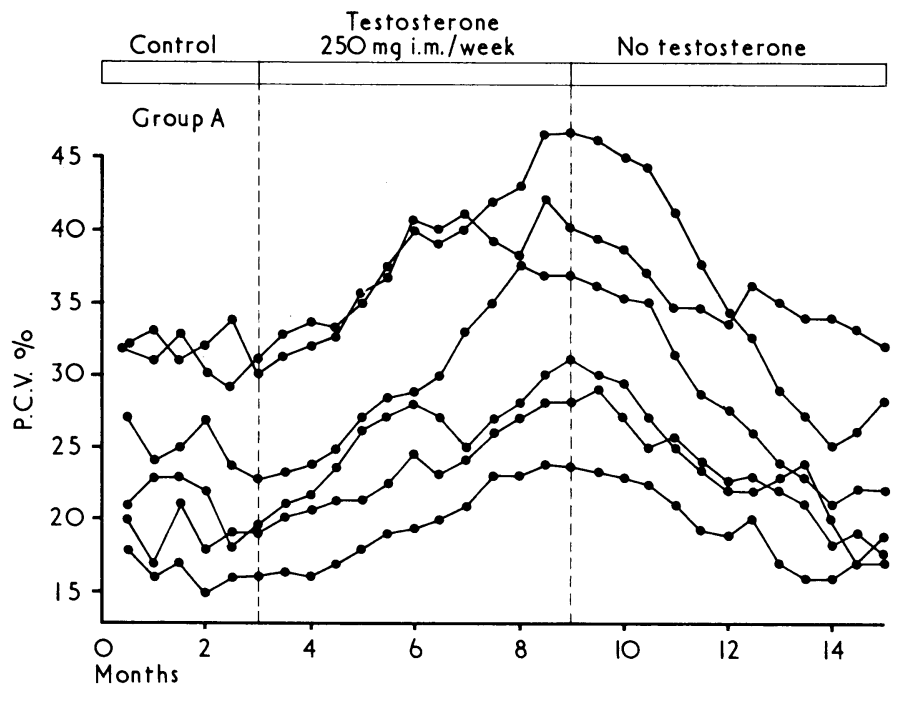

FIG 1-Response of P.C.V. to Testosterone in Group A.

TABLE II-Group B Patients

\begin{tabular}{|c|c|c|c|c|c|c|}
\hline \multirow{2}{*}{$\begin{array}{l}\text { Case } \\
\text { No. }\end{array}$} & \multirow{2}{*}{ Sex } & \multirow{2}{*}{ Age } & \multirow{2}{*}{ Disease } & \multicolumn{2}{|r|}{ P.C.V. ( $(\%)$} & \multirow[b]{2}{*}{ Androgen $\ddagger$} \\
\hline & & & & $\begin{array}{c}\text { Pre- } \\
\text { transfusion* }\end{array}$ & $\begin{array}{c}\text { Post- } \\
\text { transfusion } \dagger\end{array}$ & \\
\hline $\begin{array}{r}7 \\
8 \\
9 \\
10 \\
11 \\
12\end{array}$ & $\begin{array}{l}\mathbf{F} \\
\mathbf{M} \\
\mathbf{M} \\
\mathbf{M} \\
\mathbf{M} \\
\mathbf{M}\end{array}$ & $\begin{array}{l}40 \\
42 \\
46 \\
50 \\
34 \\
27\end{array}$ & $\begin{array}{l}\text { PN } \\
\text { GN } \\
\text { PN } \\
\text { PN } \\
\text { GN } \\
\text { PN }\end{array}$ & $\begin{array}{l}16 \\
17 \\
18 \\
19 \\
19 \\
19\end{array}$ & $\begin{array}{l}21 \\
20 \\
22 \\
23 \\
23 \\
23\end{array}$ & $\begin{array}{l}27 \\
28 \\
29 \\
32 \\
32 \\
34\end{array}$ \\
\hline & & & Mean & 18 & 22 & 30 \\
\hline
\end{tabular}

* Pretransfusion P.C.V. was admission value.

†Posttransfusion P.C. V. was obtained 24 hours after transfusion of 1-2 units packed

red cells.
$\ddagger$ Androgen P.C.V. was taken after three months' dialysis and androgen therapy.

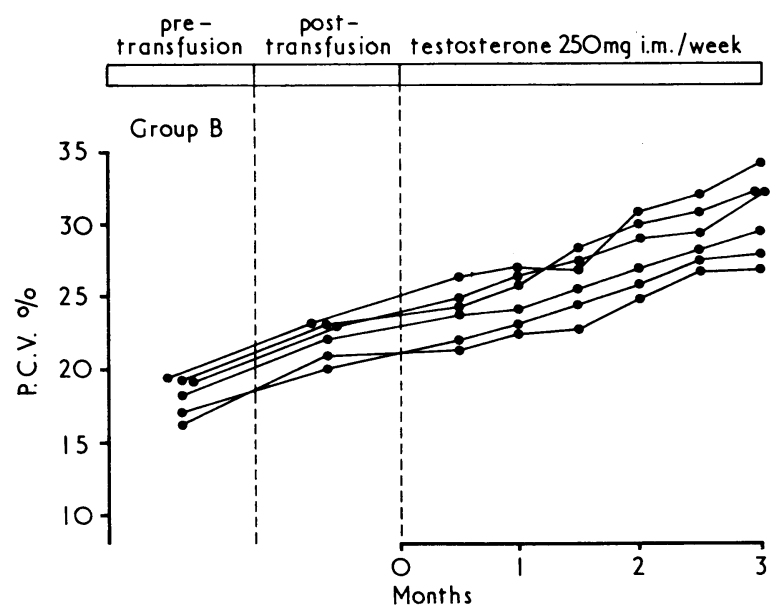

FIG 2-Response of P.C.V. to Testosterone in Group B. 
TABLE III-Group C Patients

\begin{tabular}{c|c|c|c|c|c}
\hline \multirow{2}{*}{$\begin{array}{c}\text { Case } \\
\text { No. }\end{array}$} & Sex & Age & Disease & \multicolumn{2}{|c}{ P.C.V. (\%) } \\
\cline { 5 - 6 } & & & & $\begin{array}{c}\text { Start of } \\
\text { Dialysis }\end{array}$ & $\begin{array}{c}\text { 6 months } \\
\text { Androgen }\end{array}$ \\
\hline 13 & M & 38 & PN & 18 & 28 \\
14 & M & 27 & PN & 18 & 30 \\
15 & F & 52 & Polycystic & 19 & 29 \\
16 & M & 36 & GN & 19 & 35 \\
17 & M & 55 & PN & 19 & 31 \\
18 & M & 40 & GN & 22 & 28 \\
19 & M & 39 & PN & 24 & 36 \\
20 & M & 44 & GN & 24 & 36 \\
21 & M & 56 & Polycystic & 25 & 44 \\
22 & M & 46 & Polycystic & 29 & 56 \\
\hline
\end{tabular}

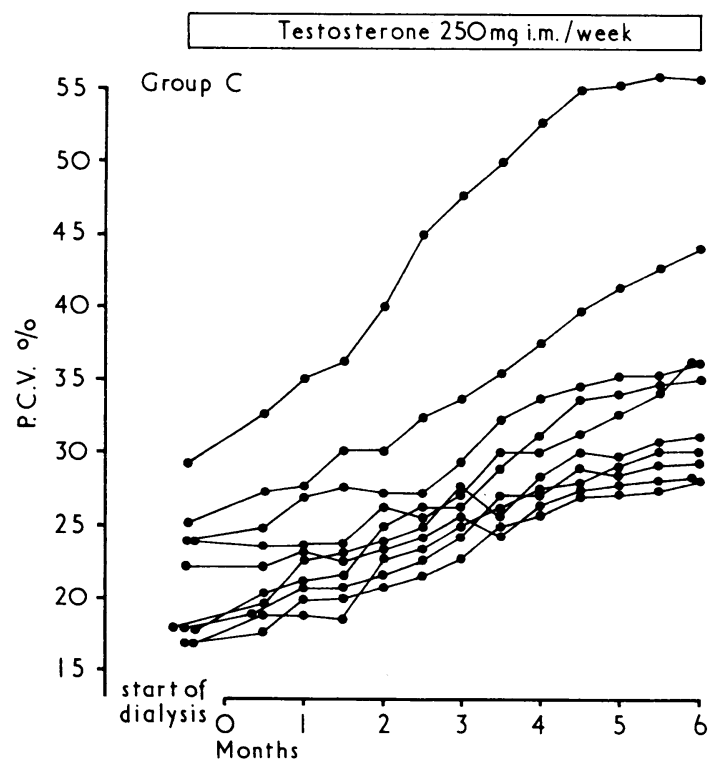

FIG 3-Response of P.C.V. to Testosterone in Group C.

TABle IV-Group D Patients

\begin{tabular}{l|c|c|c|c|c}
\hline \multirow{2}{*}{$\begin{array}{c}\text { Case } \\
\text { No. }\end{array}$} & Sex & Age & Disease & \multicolumn{2}{|c}{ P.C.V. (\%) } \\
\cline { 4 - 6 } & & & & $\begin{array}{c}\text { Control } \\
\text { BN }\end{array}$ & $\begin{array}{c}\text { Androgen } \\
\text { BN }\end{array}$ \\
\hline 23 & F & 52 & Polycystic (BN) & 15 & 22 \\
24 & M & 43 & GN (BN) & 16 & 39 \\
25 & M & 45 & PN (BN) & 17 & 23 \\
\hline \multicolumn{2}{l}{} \\
\hline
\end{tabular}

BN $=$ Bilateral nephrectomy

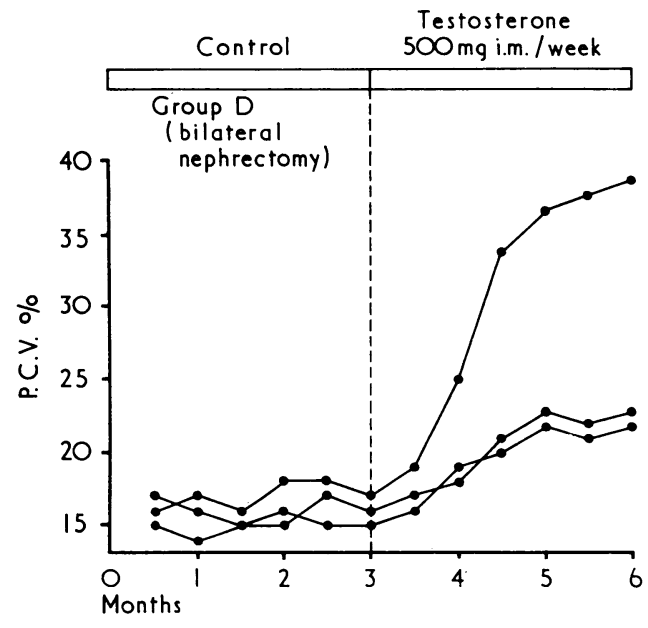

FIG 4-Response of P.C.V. to Testosterone in Group D. weekly from the start of haemodialysis. In this group there was a $50 \%$ rise in P.C.V. in six months confirmed by ${ }^{61} \mathrm{Cr}$ red cell volume measurements where the mean red cell volume $/ \mathbf{k g}$ body weight for the group rose from 15.6 to $23.7 \mathrm{ml}$. The serum iron levels in the group remained low (average $70 \mu \mathrm{g} / 100 \mathrm{ml}$ after six months' haemodialysis and 1-2 $\mathrm{g}$ of intravenous iron supplements). Though the peak responses were usually within six months, in Case 22, a polycystic patient, it was necessary to stop androgen therapy when the P.C.V. reached $56 \%$ as technical difficulties with fistula needle dialysis were becoming too great. His P.C.V. subsequently fell to $38 \%$ and he developed symptoms of fatigue and was put back on testosterone.

In group D (Table IV, Fig. 4) one patient (Case 24) with chronic glomerulonephritis, previously nephrectomized for hypertension, increased his P.C.V. from 16 to $39 \%$ in three months after starting testosterone. Cases 23 and 25 were far less dramatic but increased P.C.V. to 22 and $23 \%$ and were able to lead reasonably active lives without a transfusion requirement.

Side Effects.-Two men developed priapism while on testosterone. One woman developed baldness and hirsutes.

\section{Discussion}

The effect of testosterone on erythropoiesis has been well documented experimentally, though the mode of action is not clear. It has been suggested that it increases erythropoietin activity even in the absence of renal tissue, and this effect has been found in man (Mirand et al., 1969). These workers further suggest that the response is dose related.

During 1965-7 a trial of oral androgen (fluoxymesterone) in a dose of $0 \cdot 1-0 \cdot 3 \mathrm{mg} / \mathrm{kg}$ body weight daily resulted in a rise in P.C.V. in two out of seven patients (Shaldon unpublished data); more recently Eschbach (1969) reported some success with an oral androgen in a similar dose. However, as oral androgens are noted for their variable absorption, and patient reliability in taking oral medicaments is always suspect, it was decided to use a parenteral preparation with a much larger dose of testosterone. In addition, the potential side effects of oral methyltestosterone on the liver would be avoided. Finally, masculinizing side effects were found to be troublesome in only one out of five women, and no untoward effects occurred in the men. The following facts have emerged from this trial -namely, intramuscular testosterone given in a high dose (250-500 $\mathrm{mg}$ weekly) resulted in a rise in haemoglobin in all 25 patients studied; the effect occurred in the absence of renal tissue and after blood transfusions; and the effect was reversible on stopping the drug and therefore a maintenance dose was required for persistent effect. The serum iron levels remained low in spite of intravenous iron supplements. The relationship of this observation to androgen therapy is uncertain, as any improvement in erythropoiesis associated with effective and adequate haemodialysis would probably have led to the same result (Eschbach et al., 1970).

In attempting to draw conclusions about the effect and mode of action of a drug in the anaemia of chronic dialysis, however, one is inevitably surrounded with so many uncontrolled variables which can effect the anaemia independently of the drug that generalizations are inevitably speculative. Nevertheless, the effect of intramuscular testosterone in 25 patients under conditions which have been defined was reproducible and reversible. The risk of priapism in men on haemodialysis receiving testosterone exists. Any increase in erectile frequency is an indication for stopping the drug.

The major benefit of testosterone was seen in patients with P.C.V. below $20 \%$, when maintenance transfusions are often necessary. The ability to raise the P.C.V. above $20 \%$ in all patients on dialysis without transfusion should effectively reduce the routine transfusion policies still practised at many centres. 


\section{References}

Comty, C. M., Baillod, R. A., Crockett, R., and Shaldon, S. (1966). Proceedings of European Dialysis and Transplant Association, 3, 98.

Crockett, R. E., et al. (1967). Proceedings of European Dialysis and Transplant Association, 4, 17.

Druckker, W., Haagsma-Schouten, W. A. G., Alberts, C., and Spoek, M. G. (1969). Proceedings of European Dialysis and Transplant Association, 6, 99 .

Eschbach, J. W. (1969). Fourth International Congress of Nephrology. Abstracts of General Sessions Symposia, p. 161.

Eschbach, J. W., Cook, J. D., and Finch, C. A. (1970). Clinical Science, 38, 191 .

Fried, W., and Gurney, C. W. (1968). Annals of the New York Academy of Science, 149, 356.

Gordon, A. S., Mirand, E. A., Wenig, J., Katz, R., and Zanjani, E. D. (1968). Annals of the New York Academy of Science, 149, 318.
Killander, A., Lundmark, K. M., and Sjolin, S. (1969). Acta Paediatrica Scandinavicka, 58, 10

Lawson, D. H., Will, G., Boddy, K., and Linton, A. L. (1968). Proceedings of European Dialysis and Transplant Association, 5, 167.

Mirand, E. A., Gordon, A. S., and Wenig, J. (1965). Nature, 206, 270.

Mirand, E. A., Murphy, G. P., Steeves, R. A., Groenewald, J. M., and De Klerk, J. N. (1969). Fournal of Laboratory and Clinical Medicine, 73,121

Parsons, F. M., and Clark, P. B. (1969). Proceedings of European Dialysis and Transplant Association, 6, 217.

Shahidi, N. T., and Diamond, L. N. (1961). New England fournal Medicine, 264, 953.

Shaldon, S. (1966). Postgraduate Medical fournal, 42, 671.

Verroust, P. J., et al. (1967). Proceedings of European Dialysis and Transplant Association, 4, 12

Wright, F. K., Goldsmith, H. J., and Hall, S. M. (1968). Proceedings of European Dialysis and Transplant Association, 5, 179.

\title{
Comparative Double-blind Trial of Cephalexin and Ampicillin in Treatment of Urinary Infections
}

\author{
J. A. DAVIES, J. E. M. STRANGEWAYS, R. G. MITCHELL， L. J. BEILIN， J. G. G. LEDINGHAM, \\ J. M. HOLT
}

British Medical fournal, 1971, 3, 215-217

\section{Summary}

Cephalexin was compared with ampicillin in the treatment of urinary tract infections by a random doubleblind technique. Both drugs were found to be equally effective. In 21 out of 31 patients treated with cephalexin and in 20 out of 31 treated with ampicillin the urine was sterile three weeks after starting therapy. The bacteriological findings at one and eight weeks were also similar in both groups. No serious adverse reactions were attributable to cephalexin, which seemed to be tolerated rather better than ampicillin.

\section{Introduction}

Cephalexin is a semisynthetic cephalosporin which is effectively absorbed from the gastrointestinal tract (Griffith and Black, 1968; Gower and Dash, 1969; Davies, Strangeways, and Holt, 1970). Antibacterial activity has been demonstrated against a wide range of Gram-negative and Gram-positive organisms (Perkins, Carlisle, and Saslaw, 1968). It is excreted unchanged in the urine in high concentration (Meyers, Kaplan, and Weinstein, 1969), and preliminary investigations have suggested that it may be effective in the treatment of urinary tract infections (Leigh, Faiers, and Brumfitt, 1970). This report describes a double-blind trial designed to compare cephalexin with ampicillin in the treatment of urinary tract infections.

\section{Methods}

Sixty-four patients were studied, comprising eight men and 56 non-pregnant women aged 19 to 83 years. Pyelography

\footnotetext{
Departments of Medicine and Bacteriology, United Oxford Hospitals J. A. DAVIES, M.R.C.P., Registrar in Therapeutics

J. E. M. STRANGEWAYS, M.B., B.S., Registrar in Bacteriology

R. G. MITCHELL, D.M., M.R.C.P., Consultant Bacteriologist

L. J. BEILIN, M.D., M.R.C.P., Physician, Clinical Therapeutics Group

J. G. G. LEDINGHAM, D.M., F.R.C.P., Physician, Clinical Therapeutics

Group

J. M. HOLT, M.D., M.R.c.P., Physician, Clinical Therapeutics Group
}

showed abnormalities of the urinary tract in 10 patients Forty-eight were inpatients, and some were seriously ill due to disorders outside the urinary tract, which resulted in the deaths of four patients during the course of the study. The diagnosis of urinary tract infection was accepted when a similar organism was grown from two consecutive urine samples in a concentration of more than 100,000 organisms per ml. We excluded from the trial patients with a history of penicillin hypersensitivity, patients with indwelling urethral catheters, and patients infected with Pseudomonas aeruginosa or Proteus strains other than Proteus mirabilis, since these organisms are known to be resistant to both cephalexin (Wick, 1967), and ampicillin (Anderson, Kennedy, Plorde, Shulman, and Petersdorf, 1964). Patients were not excluded on the basis of resistance of the infecting organism to the test antibiotics on preliminary sensitivity testing.

Treatment.-Each patient received either cephalexin or ampicillin $500 \mathrm{mg}$ six-hourly for 10 days. Supplies of cephalexin and ampicillin made up by Glaxo Laboratories Ltd. in identical capsules, identified only as drugs $A$ and $B$, were held by the hospital pharmacy. Treatment was allocated at random, from a list stratified to ensure a similar proportion of uncomplicated cases in each group, and the drugs were distributed by the pharmacy in a container unmarked except for directions. The code was broken on completion of the study.

Assessment of Treatment.-Urine was cultured at one, three, and eight weeks after the beginning of the treatment. Patients were seen by one of us (J.A.D.) at the same intervals, and after one week a check was made on the number of capsules remaining, to establish that the prescribed dose was being taken. Those who relapsed were given appropriate alternative therapy and thereafter were excluded from further study.

Assessment of Adverse Reactions.-Spontaneous complaints attributed to the test drugs were recorded, and each patient was then questioned specifically about diarrhoea, flatulence, nausea, vomiting, pruritus, and rashes. The haemoglobin, white blood count, E.S.R., one-stage prothrombin time, serum urea, alkaline phosphatase, aspatate aminotransferase, and lactic dehydrogenase levels were measured before and one week after the start of treatment.

Bacteriology.-Urine specimens were cultured within two hours of voiding with the calibrated loop technique of Guttman 